\title{
Research Article \\ On Coupled Fixed Point Theorems for Nonlinear Contractions in Partially Ordered G-Metric Spaces
}

\author{
S. A. Mohiuddine and Abdullah Alotaibi \\ Department of Mathematics, Faculty of Science, King Abdulaziz University, P.O. Box 80203, \\ Jeddah 21589, Saudi Arabia \\ Correspondence should be addressed to S. A. Mohiuddine, mohiuddine@gmail.com
}

Received 31 July 2012; Revised 2 October 2012; Accepted 2 October 2012

Academic Editor: Simeon Reich

Copyright (C) 2012 S. A. Mohiuddine and A. Alotaibi. This is an open access article distributed under the Creative Commons Attribution License, which permits unrestricted use, distribution, and reproduction in any medium, provided the original work is properly cited.

Two concepts-one of the coupled fixed point and the other of the generalized metric spaceplay a very active role in recent research on the fixed point theory. The definition of coupled fixed point was introduced by Bhaskar and Lakshmikantham (2006) while the generalized metric space was introduced by Mustafa and Sims (2006). In this work, we determine some coupled fixed point theorems for mixed monotone mapping satisfying nonlinear contraction in the framework of generalized metric space endowed with partial order. We also prove the uniqueness of the coupled fixed point for such mappings in this setup.

\section{Introduction}

Fixed point theory is a very useful tool in solving variety of problems in the control theory, economic theory, nonlinear analysis and, global analysis. The Banach contraction principle [1] is the most famous, most simplest, and one of the most versatile elementary results in the fixed point theory. A huge amount of literature is witnessed on applications, generalizations, and extensions of this principle carried out by several authors in different directions, for example, by weakening the hypothesis, using different setups, and considering different mappings.

Recently, the idea of generalized metric spaces was introduced and studied by Mustafa and Sims [2] originated from the concept of metric spaces. Some fixed point theorem in this setup was first determined by Mustafa et al. [3]; particularly, the Banach contraction principle was established in this work. Since then several fixed point, coupled fixed point, and triple fixed point theorems in the framework of generalized metric spaces have been investigated in $[4-11]$. 
In the recent past, many authors obtained important fixed point theorems in partially ordered metric spaces, that is, metric spaces endowed with a partial ordering (see [12-24]).

The aim of this paper is to determine some coupled fixed point theorems for nonlinear contractions in the framework of partially ordered generalized metric spaces.

\section{Definitions and Preliminary Results}

We will assume throughout this paper that the symbol $\mathbb{R}$ and $\mathbb{N}$ will denote the set of real and natural numbers, respectively. In this section, we recall some definitions and preliminary results which we will use throughout the paper. Mustafa and Sims [2] have recently introduced the concept of generalized metric space as follows.

Let $X$ be a nonempty set and a mapping $G: X \times X \times X \rightarrow \mathbb{R}$. Then $G$ is called a generalized metric (for short, $G$-metric) on $X$ and $(X, G)$ a generalized metric space or simply $G$-metric space if the following conditions are satisfied:

(i) $G(x, y, z)=0$ if $x=y=z$,

(ii) $G(x, x, y)>0$, for all $x, y \in X$ and $x \neq y$,

(iii) $G(x, x, y) \leq G(x, y, z)$, for all $x, y, z \in X$ and $y \neq z$,

(iv) $G(x, y, z)=G(x, z, y)=G(y, z, x)=\cdots$ (symmetry in all three variables),

(v) $G(x, y, z) \leq G(x, a, a)+G(a, y, z)$, for all $x, y, z, a \in X$ (rectangle inequality).

We remark that every $G$-metric on $X$ defines a metric $d_{G}$ on $X$ by $d_{G}(x, y)=G(x, y, y)+$ $G(y, x, x)$, for all $x, y \in X$.

Example 2.1 (see [2]). Let $(X, d)$ be a metric space. The function $G: X \times X \times X \rightarrow[0, \infty)$ defined by

$$
G(x, y, z)=\max \{d(x, y), d(y, z), d(z, x)\}
$$

or

$$
G(x, y, z)=d(x, y)+d(y, z)+d(z, x)
$$

for all $x, y, z \in X$, is a $G$-metric on $X$.

The concepts of convergence and Cauchy sequences and continuous functions in Gmetric space are studied in [2].

Let $(X, G)$ be a $G$-metric space. Then, a sequence $\left(x_{n}\right)$ is said to be convergent in $(X, G)$ or simply G-convergent to $x \in X$ if for every $\epsilon>0$ there exists $N \in \mathbb{N}$ such that $G\left(x_{n}, x_{m}, x\right)<\epsilon$, for all $n, m \geq N$.

Let $(X, G)$ be a $G$-metric space. Then, $\left(x_{n}\right)$ is said to be Cauchy in $(X, G)$ or simply $G$ Cauchy if for every $\epsilon>0$ there exists $N \in \mathbb{N}$ such that $G\left(x_{n}, x_{m}, x_{k}\right)<\epsilon$, for all $n, m, k \geq N$. A G-metric space $(X, G)$ is said to be complete if every $G$-Cauchy sequence is $G$-convergent.

Let $(X, G)$ be a $G$-metric space and $f: X \rightarrow X$ a mapping. Then, $f$ is said to $G$-continuous at a point $x \in X$ if and only if it is $G$-sequentially continuous at $x$; that is, whenever $\left(x_{n}\right)$ is $G$-convergent to $x$, we have $\left(f\left(x_{n}\right)\right)$ G-convergent to $f(x)$. 
Proposition 2.2 (see [2]). Let $(X, G)$ be a G-metric space and $\left(x_{n}\right)$ a sequence in $X$. Then, for all $x \in X$, the following statements are equivalent:

(i) $\left(x_{n}\right)$ is G-convergent to $x$,

(ii) $G\left(x_{n}, x_{n}, x\right) \rightarrow 0$ as $n \rightarrow \infty$,

(iii) $G\left(x_{n}, x, x\right) \rightarrow 0$ as $n \rightarrow \infty$,

(iv) $G\left(x_{n}, x_{m}, x\right) \rightarrow 0$ as $n, m \rightarrow \infty$.

Proposition 2.3 (see $[2])$. Let $(X, G)$ be a G-metric space and $\left(x_{n}\right)$ a sequence in $X$. Then, the following statements are equivalent:

(i) $\left(x_{n}\right)$ is G-Cauchy,

(ii) For every $\epsilon>0$ there exists $N \in \mathbb{N}$ such that $G\left(x_{n}, x_{m}, x_{m}\right)<\epsilon$, for all $n, m \geq N$.

Lemma 2.4 (see [2]). If $(X, G)$ is a G-metric space then $G(x, y, y) \leq 2 G(y, x, x)$ for all $x, y \in X$.

Let $(X, G)$ be a $G$-metric space and $F: X \times X \rightarrow X$ a mapping. Then, a map $F$ is said to be continuous [10] in $(X, G)$ if for every G-convergent sequences $x_{n} \rightarrow x$ and $y_{n} \rightarrow y$, $\left(F\left(x_{n}, y_{n}\right)\right)$ is $G$-convergent to $F(x, y)$.

Quite recently, Bhaskar and Lakshmikantham [14] defined and studied the concepts of mixed monotone property and coupled fixed point in partially ordered metric space.

Let $(X, \leq)$ be a partially ordered set and $F: X \times X \rightarrow X$ a mapping. Then, a map $F$ is said to have mixed monotone property if $F(x, y)$ is monotone nondecreasing in $x$ and is monotone nonincreasing in $y$; that is, for any $x, y \in X$,

$$
\begin{array}{lll}
x_{1}, x_{2} \in X, \quad x_{1} \leq x_{2} & \text { implies } F\left(x_{1}, y\right) \leq F\left(x_{2}, y\right) \\
y_{1}, y_{2} \in X, & y_{1} \leq y_{2} \quad \text { implies } F\left(x, y_{1}\right) \geq F\left(x, y_{2}\right) .
\end{array}
$$

An element $(x, y) \in X \times X$ is said to be a coupled fixed point of the mapping $F: X \times X \rightarrow$ $X$ if

$$
F(x, y)=x, \quad F(y, x)=y \text {. }
$$

The following class of functions are considered in [25]. Denote with $\Phi$ the set of all functions $\varphi:[0, \infty) \rightarrow[0, \infty)$ which satisfy that

(i) $\varphi$ is continuous and nondecreasing,

(ii) $\varphi(t)=0$ if and only if $t=0$,

(iii) $\varphi(t+s) \leq \varphi(t)+\varphi(s)$, for all $t, s \in[0, \infty)$.

By $\Psi$ we denote the set of all functions $\psi:[0, \infty) \rightarrow(0, \infty)$ which satisfy $\lim _{t \rightarrow r} \psi(t)>$ 0 , for all $r>0$ and $\lim _{t \rightarrow 0^{+}} \psi(t)=0$. 
For example, functions $\varphi_{1}, \varphi_{2}, \varphi_{3}, \varphi_{3} \in \Phi$, where $\varphi_{1}(t)=k t(k>0), \varphi_{2}(t)=t / t+1$, $\varphi_{3}(t)=\ln (t+1)$, and $\varphi_{4}(t)=\min \{t, 1\}$, and the functions $\psi_{1}, \psi_{2}, \psi_{3} \in \Psi$, where $\psi_{1}(t)=k t$, $\psi_{2}(t)=\ln (2 t+1) / 2$, and

$$
\psi_{3}(t)= \begin{cases}1, & \text { if } t=0, t=1 \\ \frac{t}{t+1}, & \text { if } 0<t<1 \\ \frac{t}{2}, & \text { if } t>1 .\end{cases}
$$

\section{Main Results}

In this section, we establish some coupled fixed point results by considering a map on generalized metric spaces endowed with a partial order.

Theorem 3.1. Let $(X, \preceq)$ be a partially ordered set, and let $G$ be a $G$-metric on $X$ such that $(X, G)$ is a complete $G$-metric space. Suppose that there exist $\varphi \in \Phi, \psi \in \Psi$, and a mapping $F: X \times X \rightarrow X$ such that

$$
\varphi(G(F(x, y), F(u, v), F(s, t))) \leq \frac{1}{2} \varphi(G(x, u, s)+G(y, v, t))-\psi\left(\frac{G(x, u, s)+G(y, v, t)}{2}\right)
$$

for all $x, y, u, v, s, t \in X$ with $x \geq u \geq s$ and $y \leq v \leq t$ where either $u \neq s$ or $v \neq t$. Suppose $F$ has $a$ mixed monotone property and also suppose that either

(a) $F$ is continuous or

(b) X has the following property:

(i) if a nondecreasing sequence $\left(x_{n}\right)$ is G-convergent to $x$, then $x_{n} \leq x$, for all $n$,

(ii) if a nonincreasing sequence $\left(y_{n}\right)$ is G-convergent to $y$, then $y_{n} \geq y$, for all $n$.

If there exist $x_{0}, y_{0} \in X$ such that $x_{0} \leq F\left(x_{0}, y_{0}\right)$ and $y_{0} \geq F\left(y_{0}, x_{0}\right)$, then $F$ has a coupled point; that is, there exist $x, y \in X$ such that $F(x, y)=x$ and $F(y, x)=y$.

Proof. Let $x_{0}, y_{0} \in X$ be such that $x_{0} \leq F\left(x_{0}, y_{0}\right)$ and $y_{0} \geq F\left(y_{0}, x_{0}\right)$. We can choose $x_{1}, y_{1} \in X$ such that $x_{1}=F\left(x_{0}, y_{0}\right)$ and $y_{1}=F\left(y_{0}, x_{0}\right)$. Write

$$
x_{n+1}=F\left(x_{n}, y_{n}\right), \quad y_{n+1}=F\left(y_{n}, x_{n}\right),
$$

for all $n \geq 1$. Due to the mixed monotone property of $F$, we can find $x_{2} \geq x_{1} \geq x_{0}$ and $y_{2} \leq$ $y_{1} \leq y_{0}$. By straightforward calculation, we obtain

$$
\begin{aligned}
& x_{0} \leq x_{1} \leq x_{2} \leq \cdots \leq x_{n+1} \leq \cdots \\
& y_{0} \geq y_{1} \geq y_{2} \geq \cdots \geq y_{n+1} \geq \cdots
\end{aligned}
$$


Using (3.1) and (3.2), we obtain

$$
\begin{aligned}
\varphi(G( & \left.\left.x_{n+1}, x_{n+1}, x_{n}\right)\right) \\
& =\varphi\left(G\left(F\left(x_{n}, y_{n}\right), F\left(x_{n}, y_{n}\right), F\left(x_{n-1}, y_{n-1}\right)\right)\right) \\
& \leq \frac{1}{2} \varphi\left(G\left(x_{n}, x_{n}, x_{n-1}\right)+G\left(y_{n}, y_{n}, y_{n-1}\right)\right)-\psi\left(\frac{G\left(x_{n}, x_{n}, x_{n-1}\right)+G\left(y_{n}, y_{n}, y_{n-1}\right)}{2}\right),
\end{aligned}
$$

and similarly

$$
\begin{aligned}
\varphi(G( & \left.\left.y_{n+1}, y_{n+1}, y_{n}\right)\right) \\
\quad & \varphi\left(G\left(F\left(y_{n}, x_{n}\right), F\left(y_{n}, x_{n}\right), F\left(y_{n-1}, x_{n-1}\right)\right)\right) \\
\quad \leq & \frac{1}{2} \varphi\left(G\left(y_{n}, y_{n}, y_{n-1}\right)+G\left(x_{n}, x_{n}, x_{n-1}\right)\right)-\psi\left(\frac{G\left(y_{n}, y_{n}, y_{n-1}\right)+G\left(x_{n}, x_{n}, x_{n-1}\right)}{2}\right) .
\end{aligned}
$$

Adding (3.4) and (3.5), we get

$$
\begin{aligned}
& \varphi\left(G\left(x_{n+1}, x_{n+1}, x_{n}\right)\right)+\varphi\left(G\left(y_{n+1}, y_{n+1}, y_{n}\right)\right) \\
& \leq \varphi\left(G\left(x_{n}, x_{n}, x_{n-1}\right)+G\left(y_{n}, y_{n}, y_{n-1}\right)\right) \\
& \quad-2 \psi\left(\frac{G\left(x_{n}, x_{n}, x_{n-1}\right)+G\left(y_{n}, y_{n}, y_{n-1}\right)}{2}\right) .
\end{aligned}
$$

Using the property $\varphi(t+s) \leq \varphi(t)+\varphi(s)$ for all $t, s \in[0, \infty)$, we get

$$
\begin{aligned}
& \varphi\left(G\left(x_{n+1}, x_{n+1}, x_{n}\right)+G\left(y_{n+1}, y_{n+1}, y_{n}\right)\right) \\
& \quad \leq \varphi\left(G\left(x_{n}, x_{n}, x_{n-1}\right)+G\left(y_{n}, y_{n}, y_{n-1}\right)\right)-2 \varphi\left(\frac{G\left(x_{n}, x_{n}, x_{n-1}\right)+G\left(y_{n}, y_{n}, y_{n-1}\right)}{2}\right)
\end{aligned}
$$

which implies that

$$
\varphi\left(G\left(x_{n+1}, x_{n+1}, x_{n}\right)+G\left(y_{n+1}, y_{n+1}, y_{n}\right)\right) \leq \varphi\left(G\left(x_{n}, x_{n}, x_{n-1}\right)+G\left(y_{n}, y_{n}, y_{n-1}\right)\right)
$$

Since $\varphi$ is nondecreasing, we have

$$
G\left(x_{n+1}, x_{n+1}, x_{n}\right)+G\left(y_{n+1}, y_{n+1}, y_{n}\right) \leq G\left(x_{n}, x_{n}, x_{n-1}\right)+G\left(y_{n}, y_{n}, y_{n-1}\right) .
$$


For all $n \in \mathbb{N}$, set

$$
s_{n}=G\left(x_{n+1}, x_{n+1}, x_{n}\right)+G\left(y_{n+1}, y_{n+1}, y_{n}\right),
$$

then a sequence $\left(s_{n}\right)$ is decreasing. Therefore, there exists some $s \geq 0$ such that

$$
\lim _{n \rightarrow \infty} s_{n}=\lim _{n \rightarrow \infty}\left[G\left(x_{n+1}, x_{n+1}, x_{n}\right)+G\left(y_{n+1}, y_{n+1}, y_{n}\right)\right]=s
$$

Now we have to show that $s=0$. On the contrary, suppose that $s>0$. Letting $n \rightarrow \infty$ in (3.7) (equivalently, $s_{n}$ is G-convergent to $s$ ) and using the property of $\varphi$ and $\psi$, we get

$$
\varphi(s)=\lim _{n \rightarrow \infty} \varphi\left(s_{n}\right) \leq \lim _{n \rightarrow \infty}\left\{\varphi\left(s_{n-1}\right)-2 \psi\left(\frac{s_{n-1}}{2}\right)\right\}=\varphi(s)-2 \lim _{s_{n-1} \rightarrow s} \psi\left(\frac{s_{n-1}}{2}\right)<\varphi(s),
$$

which is a contradiction. Thus $s=0$; from (3.11), we have

$$
\lim _{n \rightarrow \infty} s_{n}=\lim _{n \rightarrow \infty}\left[G\left(x_{n+1}, x_{n+1}, x_{n}\right)+G\left(y_{n+1}, y_{n+1}, y_{n}\right)\right]=0
$$

Again, we have to show that $\left(x_{n}\right)$ and $\left(y_{n}\right)$ are Cauchy sequences in the $G$-metric space $(X, G)$. On the contrary, suppose that at least one of $\left(x_{n}\right)$ or $\left(y_{n}\right)$ is not a Cauchy sequence in $(X, G)$. Then there exists $\epsilon>0$, for which we can find subsequences $\left(x_{k(j)}\right),\left(x_{l(j)}\right)$ and $\left(y_{k(j)}\right),\left(y_{l(j)}\right)$ of the sequences $\left(x_{n}\right)$ and $\left(y_{n}\right)$, respectively, with $k(j)>l(j) \geq j$, for all $j \in \mathbb{N}$ such that

$$
\alpha_{j}=G\left(x_{k(j)}, x_{k(j)}, x_{l(j)}\right)+G\left(y_{k(j)}, y_{k(j)}, y_{l(j)}\right) \geq \epsilon
$$

We may also assume that

$$
G\left(x_{k(j)-1}, x_{k(j)-1}, x_{l(j)}\right)+G\left(y_{k(j)-1}, y_{k(j)-1}, y_{l(j)}\right)<\epsilon,
$$

by choosing $k(j)$ to be the smallest number exceeding $l(j)$, for which (3.14) holds. From (3.14) and (3.15) and using the rectangle inequality, we obtain

$$
\begin{aligned}
\epsilon \leq & \alpha_{j}=G\left(x_{k(j)}, x_{k(j)}, x_{l(j)}\right)+G\left(y_{k(j)}, y_{k(j)}, y_{l(j)}\right) \\
\leq & G\left(x_{k(j)}, x_{k(j)}, x_{k(j)-1}\right)+G\left(x_{k(j)-1}, x_{k(j)-1}, x_{l(j)}\right) \\
& +G\left(y_{k(j)}, y_{k(j)}, y_{k(j)-1}\right)+G\left(y_{k(j)-1}, y_{k(j)-1}, y_{l(j)}\right) \\
< & G\left(x_{k(j)}, x_{k(j)}, x_{k(j)-1}\right)+G\left(y_{k(j)}, y_{k(j)}, y_{k(j)-1}\right)+\epsilon .
\end{aligned}
$$

Letting $j \rightarrow \infty$ in the above inequality and using (3.13), we get

$$
\lim _{j \rightarrow \infty} \alpha_{j}=\lim _{j \rightarrow \infty}\left[G\left(x_{k(j)}, x_{k(j)}, x_{l(j)}\right)+G\left(y_{k(j)}, y_{k(j)}, y_{l(j)}\right)\right]=\epsilon
$$


Again, by using rectangle inequality, we obtain

$$
\begin{aligned}
\alpha_{j}= & G\left(x_{k(j)}, x_{k(j)}, x_{l(j)}\right)+G\left(y_{k(j)}, y_{k(j)}, y_{l(j)}\right) \\
\leq & G\left(x_{k(j)}, x_{k(j)}, x_{k(j)+1}\right)+G\left(x_{k(j)+1}, x_{k(j)+1}, x_{l(j)+1}\right)+G\left(x_{l(j)+1}, x_{l(j)+1}, x_{l(j)}\right) \\
& +G\left(y_{k(j)}, y_{k(j)}, y_{k(j)+1}\right)+G\left(y_{k(j)+1}, y_{k(j)+1}, y_{l(j)+1}\right)+G\left(y_{l(j)+1}, y_{l(j)+1}, y_{l(j)}\right) \\
= & s_{l(j)}+G\left(x_{k(j)}, x_{k(j)}, x_{k(j)+1}\right)+G\left(x_{k(j)+1}, x_{k(j)+1}, x_{l(j)+1}\right) \\
& +G\left(y_{k(j)}, y_{k(j)}, y_{k(j)+1}\right)+G\left(y_{k(j)+1}, y_{k(j)+1}, y_{l(j)+1}\right)
\end{aligned}
$$

By using Lemma 2.4, the above inequality becomes

$$
\begin{aligned}
\alpha_{j} \leq & s_{l(j)}+2 G\left(x_{k(j)+1}, x_{k(j)+1}, x_{k(j)}\right)+2 G\left(y_{k(j)+1}, y_{k(j)+1}, y_{k(j)}\right) \\
& +G\left(x_{k(j)+1}, x_{k(j)+1}, x_{l(j)+1}\right)+G\left(y_{k(j)+1}, y_{k(j)+1}, y_{l(j)+1}\right)
\end{aligned}
$$

this implies that

$$
\alpha_{j} \leq s_{l(j)}+2 s_{k(j)}+G\left(x_{k(j)+1}, x_{k(j)+1}, x_{l(j)+1}\right)+G\left(y_{k(j)+1}, y_{k(j)+1}, y_{l(j)+1}\right)
$$

Operating $\varphi$ on both sides of the above inequality,

$$
\begin{aligned}
\varphi\left(\alpha_{j}\right) & \leq \varphi\left(s_{l(j)}+2 s_{k(j)}+G\left(x_{k(j)+1}, x_{k(j)+1}, x_{l(j)+1}\right)+G\left(y_{k(j)+1}, y_{k(j)+1}, y_{l(j)+1}\right)\right) \\
& =\varphi\left(s_{l(j)}+2 s_{k(j)}\right)+\varphi\left(G\left(x_{k(j)+1}, x_{k(j)+1}, x_{l(j)+1}\right)\right)+\varphi\left(G\left(y_{k(j)+1}, y_{k(j)+1}, y_{l(j)+1}\right)\right) .
\end{aligned}
$$

Now we find the expressions $\varphi\left(G\left(x_{k(j)+1}, x_{k(j)+1}, x_{l(j)+1}\right)\right)$ and $\varphi\left(G\left(y_{k(j)+1}, y_{k(j)+1}, y_{l(j)+1}\right)\right)$ in terms of $\varphi$ and $\psi$ by using (3.1) and (3.2); that is,

$$
\begin{aligned}
\varphi\left(G\left(x_{k(j)+1}, x_{k(j)+1}, x_{l(j)+1}\right)\right)= & \varphi\left(G\left(F\left(x_{k(j)}, y_{k(j)}\right), F\left(x_{k(j)}, y_{k(j)}\right), F\left(x_{l(j)}, y_{l(j)}\right)\right)\right) \\
\leq & \frac{1}{2} \varphi\left(G\left(x_{k(j)}, x_{k(j)}, x_{l(j)}\right)+G\left(y_{k(j)}, y_{k(j)}, y_{l(j)}\right)\right) \\
& -\psi\left(\frac{G\left(x_{k(j)}, x_{k(j)}, x_{l(j)}\right)+G\left(y_{k(j)}, y_{k(j)}, y_{l(j)}\right)}{2}\right), \\
\varphi\left(G\left(y_{k(j)+1}, y_{k(j)+1}, y_{l(j)+1}\right)\right)= & \varphi\left(G\left(F\left(y_{k(j)}, x_{k(j)}\right), F\left(y_{k(j)}, x_{k(j)}\right), F\left(y_{l(j)}, x_{l(j)}\right)\right)\right) \\
\leq & \frac{1}{2} \varphi\left(G\left(y_{k(j)}, y_{k(j)}, y_{l(j)}\right)+G\left(x_{k(j)}, x_{k(j)}, x_{l(j)}\right)\right) \\
& -\psi\left(\frac{G\left(y_{k(j)}, y_{k(j)}, y_{l(j)}\right)+G\left(x_{k(j)}, x_{k(j)}, x_{l(j)}\right)}{2}\right) .
\end{aligned}
$$


Adding (3.22) and (3.23), we get

$$
\varphi\left(G\left(x_{k(j)+1}, x_{k(j)+1}, x_{l(j)+1}\right)\right)+\varphi\left(G\left(y_{k(j)+1}, y_{k(j)+1}, y_{l(j)+1}\right)\right) \leq \varphi\left(\alpha_{j}\right)-2 \psi\left(\frac{\alpha_{j}}{2}\right) .
$$

From (3.21) and (3.24), we obtain

$$
\varphi\left(\alpha_{j}\right) \leq \varphi\left(s_{l(j)}+2 s_{k(j)}\right)+\varphi\left(\alpha_{j}\right)-2 \psi\left(\frac{\alpha_{j}}{2}\right) .
$$

Taking limit as $j \rightarrow \infty$ on both sides of the above inequality, we get

$$
\varphi(\epsilon) \leq \varphi(0)+\varphi(\epsilon)-2 \lim _{j \rightarrow \infty} \psi\left(\frac{\alpha_{j}}{2}\right)=\varphi(\epsilon)-2 \lim _{\alpha_{j} \rightarrow \epsilon} \psi\left(\frac{\alpha_{j}}{2}\right)<\varphi(\epsilon),
$$

which is a contradiction, and hence $\left(x_{n}\right)$ and $\left(y_{n}\right)$ are Cauchy sequences in the $G$-metric space $(X, G)$. Since $(X, G)$ is complete $G$-metric space, hence $\left(x_{n}\right)$ and $\left(y_{n}\right)$ are $G$-convergent. Then, there exist $x, y \in X$ such that $\left(x_{n}\right)$ and $\left(y_{n}\right)$ are $G$-convergent to $x$ and $y$, respectively. Suppose that condition (a) holds. Letting $n \rightarrow \infty$ in (3.2), we get $x=F(x, y)$ and $y=F(y, x)$. Lastly, suppose that assumption (b) holds. Since a sequence $\left(x_{n}\right)$ is nondecreasing and G-convergent to $x$ and also $\left(y_{n}\right)$ is nonincreasing sequence and G-convergent to $y$, by assumption (b), we have $x_{n} \preceq x$ and $y_{n} \geq y$ for all $n$. Using the rectangle inequality, write

$$
\begin{aligned}
G(x, x, F(x, y)) & \leq G\left(x, x, x_{n+1}\right)+G\left(x_{n+1}, x_{n+1}, F(x, y)\right) \\
& =G\left(x, x, x_{n+1}\right)+G\left(F\left(x_{n}, y_{n}\right), F\left(x_{n}, y_{n}\right), F(x, y)\right) .
\end{aligned}
$$

Applying the function $\varphi$ on both sides of the above equation and using (3.1), we have

$$
\begin{aligned}
\varphi(G(x, x, F(x, y))) \leq & \varphi\left(G\left(x, x, x_{n+1}\right)\right)+\varphi\left(G\left(F\left(x_{n}, y_{n}\right), F\left(x_{n}, y_{n}\right), F(x, y)\right)\right) \\
\leq & \varphi\left(G\left(x, x, x_{n+1}\right)\right)+\frac{1}{2} \varphi\left(G\left(x_{n}, x_{n}, x\right)+G\left(y_{n}, y_{n}, y\right)\right) \\
& -\psi\left(\frac{G\left(x_{n}, x_{n}, x\right)+G\left(y_{n}, y_{n}, y\right)}{2}\right) .
\end{aligned}
$$

Letting $n \rightarrow \infty$, we get $G(x, x, F(x, y))=0$. Hence $x=F(x, y)$. Similarly we obtain $y=$ $F(y, x)$. Thus, we conclude that $F$ has a coupled fixed point.

Corollary 3.2. Let $(X, \preceq)$ be a partially ordered set, and let $G$ be a $G$-metric on $X$ such that $(X, G)$ is a complete G-metric space. Suppose that $F: X \times X \rightarrow X$ is a mapping having mixed monotone property. Assume that there exists $\psi \in \Psi$ such that for all $x, y, u, v, s, t \in X$,

$$
G(F(x, y), F(u, v), F(s, t)) \leq \frac{G(x, u, s)+G(y, v, t)}{2}-\psi\left(\frac{G(x, u, s)+G(y, v, t)}{2}\right)
$$


with $x \geq u \geq s$ and $y \leq v \leq t$ where either $u \neq s$ or $v \neq t$. Suppose that either

(a) $F$ is continuous or

(b) X has the following property:

(i) if a nondecreasing sequence $\left(x_{n}\right)$ is G-convergent to $x$, then $x_{n} \leq x$, for all $n$,

(ii) if a nonincreasing sequence $\left(y_{n}\right)$ is G-convergent to $y$, then $y_{n} \geq y$, for all $n$.

If there exist $x_{0}, y_{0} \in X$ such that $x_{0} \leq F\left(x_{0}, y_{0}\right)$ and $y_{0} \geq F\left(y_{0}, x_{0}\right)$, then there exist $x, y \in X$ such that $F(x, y)=x$ and $F(y, x)=y$; that is, $F$ has a coupled point in $X$.

Proof. Taking $\varphi(t)=t$ in Theorem 3.1 and proceeding the same lines as in this theorem, we get the desired result.

Corollary 3.3. Let $(X, \preceq)$ be a partially ordered set, and let $G$ be a G-metric on $X$ such that $(X, G)$ is a complete G-metric space. Suppose $F: X \times X \rightarrow X$ is a mapping having mixed monotone property and assume that there exists $k \in[0,1)$ such that

$$
G(F(x, y), F(u, v), F(s, t)) \leq \frac{k}{2}[G(x, u, s)+G(y, v, t)]
$$

for all $x, y, u, v, s, t \in X$ with $x \geq u \geq s$ and $y \leq v \leq t$ where either $u \neq s$ or $v \neq t$. Suppose that either

(a) $F$ is continuous or

(b) X has the following property:

(i) if a nondecreasing sequence $\left(x_{n}\right)$ is G-convergent to $x$, then $x_{n} \leq x$, for all $n$,

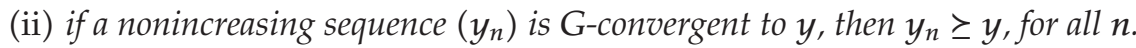

If there exist $x_{0}, y_{0} \in X$ such that $x_{0} \leq F\left(x_{0}, y_{0}\right)$ and $y_{0} \geq F\left(y_{0}, x_{0}\right)$, then $F$ has a coupled point in $X$.

Proof. Taking $\varphi(t)=t$ and $\psi(t)=((1-k) / 2) t$ in Theorem 3.1 and proceeding the same lines as in this theorem, we get the desired result.

Remark 3.4. To assure the uniqueness of a coupled fixed point, we shall consider the following condition. If $(Y, \preceq)$ is a partially ordered set, we endowed the product $Y \times Y$ with

$$
(x, y) \preceq(u, v) \text { iff } x \preceq u, y \geq v,
$$

for all $(x, y),(u, v) \in Y \times Y$.

Theorem 3.5. In addition to the hypothesis of Theorem 3.1, suppose that for all $(x, y),(s, t) \in X \times X$, there exists $(u, v) \in X \times X$ such that $(F(u, v), F(v, u))$ is comparable with $(F(x, y), F(y, x))$ and $(F(s, t), F(t, s))$. Then, $F$ has a unique coupled fixed point.

Proof. It follows from Theorem 3.1 that the set of coupled fixed points is nonempty. Suppose $(x, y)$ and $(s, t)$ are coupled fixed points of the mappings $F: X \times X \rightarrow X$; that is, $x=F(x, y)$, $y=F(y, x)$, and $s=F(s, t), t=F(t, s)$. By assumption there exists $(u, v)$ in $X \times X$ such 
that $(F(u, v), F(v, u))$ is comparable to $(F(x, y), F(y, x))$ and $(F(s, t), F(t, s))$. Put $u=u_{0}$ and $v=v_{0}$ and choose $u_{1}, v_{1} \in X$ such that $u_{1}=F\left(u_{1}, v_{1}\right)$ and $v_{1}=F\left(v_{1}, u_{1}\right)$. Thus, we can define two sequences $\left(u_{n}\right)$ and $\left(v_{n}\right)$ as

$$
u_{n+1}=F\left(u_{n}, v_{n}\right), \quad v_{n+1}=F\left(v_{n}, u_{n}\right) .
$$

Since $(u, v)$ is comparable to $(x, y)$, we can assume that $(x, y) \geq(u, v)=\left(u_{0}, v_{0}\right)$. Then it is easy to show that $\left(u_{n}, v_{n}\right)$ and $(x, y)$ are comparable; that is, $(x, y) \geq\left(u_{n}, v_{n}\right)$, for all $n$. Thus, from (3.1), we have

$$
\begin{aligned}
\varphi\left(G\left(u_{u+1}, x, x\right)\right) & =\varphi\left(G\left(F\left(u_{u}, v_{n}\right), F(x, y), F(x, y)\right)\right) \\
& \leq \frac{1}{2} \varphi\left(G\left(u_{n}, x, x\right)+G\left(v_{n}, y, y\right)\right)-\psi\left(\frac{G\left(u_{n}, x, x\right)+G\left(v_{n}, y, y\right)}{2}\right), \\
\varphi\left(G\left(y, y, v_{u+1}\right)\right) & =\varphi\left(G\left(F(y, x), F(y, x), F\left(v_{u}, u_{n}\right)\right)\right) \\
& \leq \frac{1}{2} \varphi\left(G\left(y, y, v_{n}\right)+G\left(x, x, u_{n}\right)\right)-\psi\left(\frac{G\left(y, y, v_{n}\right)+G\left(x, x, u_{n}\right)}{2}\right) .
\end{aligned}
$$

Using the property of $\varphi$ and adding (3.33) and (3.34), we get

$$
\begin{aligned}
\varphi\left(G\left(u_{u+1}, x, x\right)+G\left(v_{u+1}, y, y\right)\right) \leq & \varphi\left(G\left(u_{n}, x, x\right)+G\left(v_{n}, y, y\right)\right) \\
& -2 \psi\left(\frac{G\left(u_{n}, x, x\right)+G\left(v_{n}, y, y\right)}{2}\right)
\end{aligned}
$$

which implies that

$$
\varphi\left(G\left(u_{u+1}, x, x\right)+G\left(v_{u+1}, y, y\right)\right) \leq \varphi\left(G\left(u_{n}, x, x\right)+G\left(v_{n}, y, y\right)\right)
$$

Therefore,

$$
G\left(u_{u+1}, x, x\right)+G\left(v_{u+1}, y, y\right) \leq G\left(u_{n}, x, x\right)+G\left(v_{n}, y, y\right) .
$$

We see that the sequence $\left(G\left(u_{n}, x, x\right)+G\left(v_{n}, y, y\right)\right)$ is decreasing; there exists some $\xi \geq 0$ such that

$$
\lim _{n \rightarrow \infty}\left[G\left(u_{n}, x, x\right)+G\left(v_{n}, y, y\right)\right]=\xi
$$


Now we have to show that $\xi=0$. On the contrary, suppose that $\xi>0$. Letting $n \rightarrow \infty$ in (3.35), we get

$$
\varphi(\xi) \leq \varphi(\xi)-2 \psi \lim _{n \rightarrow \infty}\left(\frac{G\left(u_{n}, x, x\right)+G\left(v_{n}, y, y\right)}{2}\right)<\varphi(\xi)
$$

which is not possible. Hence $\xi=0$. Therefore, (3.38) becomes

$$
\lim _{n \rightarrow \infty}\left[G\left(u_{n}, x, x\right)+G\left(v_{n}, y, y\right)\right]=0,
$$

which implies

$$
\lim _{n \rightarrow \infty} G\left(u_{n}, x, x\right)=0=\lim _{n \rightarrow \infty} G\left(v_{n}, y, y\right) .
$$

Similarly, we can show that $\lim _{n \rightarrow \infty} G\left(u_{n}, s, s\right)=0=\lim _{n \rightarrow \infty} G\left(v_{n}, t, t\right)$. We conclude that $x=s$ and $y=t$. Thus, $F$ has a unique coupled fixed point.

Theorem 3.6. In addition to the hypothesis of Theorem 3.1, suppose that $x_{0}$ and $y_{0}$ are comparable. Then, F has a unique fixed point.

Proof. Proceeding the same lines as in the proof of Theorem 3.1, we know that a mapping $F: X \times X \rightarrow X$ has a coupled fixed point $(x, y)$. Now we need to show that $x=y$. Since $x_{0}$ and $y_{0}$ are comparable, we can assume that $x_{0} \geq y_{0}$. It is easy to show that $x_{n} \geq y_{n}$ for all $n \geq 0$, where $x_{n+1}=F\left(x_{n}, y_{n}\right)$ and $y_{n+1}=F\left(y_{n}, x_{n}\right)$. Suppose that $G(x, x, y)>0$, for all $x, y \in X$ with $x \neq y$. Using the rectangle inequality, write

$$
\begin{aligned}
G(x, x, y) & \leq G\left(x, x, x_{n+1}\right)+G\left(x_{n+1}, x_{n+1}, y_{n+1}\right)+G\left(y_{n+1}, y_{n+1}, y\right) \\
& =G\left(x, x, x_{n+1}\right)+G\left(F\left(x_{n}, y_{n}\right), F\left(x_{n}, y_{n}\right), F\left(y_{n}, x_{n}\right)\right)+G\left(y_{n+1}, y_{n+1}, y\right) .
\end{aligned}
$$

Operating $\varphi$ on both sides of the above inequality, we get

$$
\varphi(G(x, x, y)) \leq \varphi\left(G\left(x, x, x_{n+1}\right)+G\left(y_{n+1}, y_{n+1}, y\right)\right)+\varphi\left(G\left(F\left(x_{n}, y_{n}\right), F\left(x_{n}, y_{n}\right), F\left(y_{n}, x_{n}\right)\right)\right)
$$

From (3.1), we have

$$
\begin{aligned}
\varphi(G(x, x, y)) \leq & \varphi\left(G\left(x, x, x_{n+1}\right)+G\left(y_{n+1}, y_{n+1}, y\right)\right) \\
& +\frac{1}{2} \varphi\left(G\left(x_{n}, x_{n}, y_{n}\right)+G\left(y_{n}, y_{n}, x_{n}\right)\right)-\psi\left(\frac{G\left(x_{n}, x_{n}, y_{n}\right)+G\left(y_{n}, y_{n}, x_{n}\right)}{2}\right)
\end{aligned}
$$


Similarly, we obtain

$$
\begin{aligned}
\varphi(G(y, y, x)) \leq & \varphi\left(G\left(y, y, y_{n+1}\right)+G\left(x_{n+1}, x_{n+1}, x\right)\right) \\
& +\frac{1}{2} \varphi\left(G\left(y_{n}, y_{n}, x_{n}\right)+G\left(x_{n}, x_{n}, y_{n}\right)\right)-\psi\left(\frac{G\left(y_{n}, y_{n}, x_{n}\right)+G\left(x_{n}, x_{n}, y_{n}\right)}{2}\right) .
\end{aligned}
$$

Adding (3.44) and (3.45) and using the property of $\varphi$, we get

$$
\begin{aligned}
& \varphi(G(x, x, y)+G(y, y, x)) \\
& \leq \varphi\left(G\left(x, x, x_{n+1}\right)+G\left(y_{n+1}, y_{n+1}, y\right)\right)+\varphi\left(G\left(y, y, y_{n+1}\right)+G\left(x_{n+1}, x_{n+1}, x\right)\right) \\
&+\varphi\left(G\left(x_{n}, x_{n}, y_{n}\right)+G\left(y_{n}, y_{n}, x_{n}\right)\right)-2 \psi\left(\frac{G\left(x_{n}, x_{n}, y_{n}\right)+G\left(y_{n}, y_{n}, x_{n}\right)}{2}\right) .
\end{aligned}
$$

Letting $n \rightarrow \infty$ in the above inequality, we get

$$
\begin{aligned}
\varphi(G(x, x, y)+G(y, y, x)) \leq & \varphi(0)+\varphi(0)+\varphi(G(x, x, y)+G(y, y, x)) \\
& -2 \lim _{n \rightarrow \infty} \psi\left(\frac{G\left(x_{n}, x_{n}, y_{n}\right)+G\left(y_{n}, y_{n}, x_{n}\right)}{2}\right),
\end{aligned}
$$

which implies that

$$
\varphi(G(x, x, y)+G(y, y, x))<\varphi(G(x, x, y)+G(y, y, x))
$$

which is not possible, and hence $G(x, x, y)=0$. Thus $x=y$, whence the result.

Theorem 3.7. Let $(X, \preceq)$ be a partially ordered set, and let $G$ be a $G$-metric on $X$ such that $(X, G)$ is a complete G-metric space. Let $F: X \times X \rightarrow X$ be a mapping such that $F$ has a mixed monotone property and $F(x, y) \leq F(y, x)$ whenever $x \leq y$. Suppose that there exist $\varphi \in \Phi$ and $\psi \in \Psi$ such that for all $x, y, u, v, s, t \in X$, (3.1) holds with $x \geq u \geq s, y \leq v \leq t$ and $x<y$ where either $u \neq s$ or $v \neq t$. Assume that either

(a) $F$ is continuous or

(b) X has the following property:

(i) if a nondecreasing sequence $\left(x_{n}\right)$ is G-convergent to $x$, then $x_{n} \leq x$, for all $n$,

(ii) if a nonincreasing sequence $\left(y_{n}\right)$ is $G$-convergent to $y_{\text {, then }} y_{n} \geq y$, for all $n$.

If there exist $x_{0}, y_{0} \in X$ such that $x_{0} \leq y_{0}, x_{0} \leq F\left(x_{0}, y_{0}\right)$ and $y_{0} \geq F\left(y_{0}, x_{0}\right)$, then $F$ has a coupled point; that is, there exist $x, y \in X$ such that $F(x, y)=x$ and $F(y, x)=y$. 
Proof. Let $x_{0}, y_{0} \in X$ be such that $x_{0} \preceq F\left(x_{0}, y_{0}\right)$ and $y_{0} \geq F\left(y_{0}, x_{0}\right)$. We can choose $x_{1}, y_{1} \in X$ such that $x_{1}=F\left(x_{0}, y_{0}\right) \geq x_{0}$ and $y_{1}=F\left(y_{0}, x_{0}\right) \preceq y_{0}$. Since $x_{0} \leq y_{0}$, we have $F\left(x_{0}, y_{0}\right) \preceq$ $F\left(y_{0}, x_{0}\right)$. Accordingly,

$$
x_{0} \preceq x_{1}=F\left(x_{0}, y_{0}\right) \preceq F\left(y_{0}, x_{0}\right)=y_{1} \preceq y_{0} .
$$

Continuing this process, we can construct two sequences $\left(x_{n}\right)$ and $\left(y_{n}\right)$ in $X$ such that

$$
x_{n} \preceq F\left(x_{n}, y_{n}\right)=x_{n+1} \preceq y_{n+1}=F\left(y_{n}, x_{n}\right) \preceq y_{n},
$$

for all $n \geq 0$. Therefore,

$$
x_{0} \preceq x_{1} \leq x_{2} \preceq \cdots \preceq x_{n} \preceq x_{n+1} \cdots \preceq y_{n+1} \leq y_{n} \preceq \cdots \preceq y_{2} \leq y_{1} \leq y_{0} .
$$

The rest of the proof can be done on the same lines as in Theorem 3.1.

\section{Example and the Concluding Remark}

In the following, we construct an example of a G-metric space involving the idea of coupled fixed point to see the applicability of our results.

Let $X=\mathbb{N} \cup\{0\}$. Define a mapping $G$ from $X^{3}$ to $\mathbb{R}$ by

$$
G(x, y, z)= \begin{cases}x+y+z, & \text { if } x, y, z \text { are all distinct and different from zero, } \\ x+z, & \text { if } x=y \neq z \text { and all are different from zero, } \\ y+z+1, & \text { if } x=0, y \neq z \text { and } y, z \text { are different from zero } \\ y+2, & \text { if } x=0, y=z \neq 0, \\ z+1, & \text { if } x=0=y, z \neq 0, \\ 0, & \text { if } x=y=z\end{cases}
$$

Then $(X, G)$ is a complete $G$-metric space [10]. Let us consider a partial order $\preceq$ on $X$ be such that $x \leq y$ holds if $x>y, 3$ divides $(x-y)$, and $3 \leq 1$ and $0 \leq 1$ hold, for all $x, y \in X$. Consider a mapping $F: X \times X \rightarrow X$ defined by

$$
F(x, y)= \begin{cases}1, & \text { if } x<y \\ 0, & \text { otherwise }\end{cases}
$$

Suppose that $s \leq u \leq x<y \leq v \leq t$ holds. Therefore, we have $F(x, y)=1=F(u, v)=F(s, t)$. It follows that $G(F(x, y), F(u, v), F(s, t))=0$.

Now, applying the function $\varphi$ to this equality and then using the hypothesis of this function, we see that (3.1) is satisfied since the left-hand side of (3.1) becomes 0 . For $x_{0}=81$ and $y_{0}=0$, Theorem 3.7 is applicable. In this case, the coupled fixed point is not unique. Hence $(0,0)$ and $(1,0)$ are two coupled fixed points of $F$.

We remark that inequality (3.1) is not satisfied when $s=u=x=y=3, v=0$, and $t=1$, and hence Theorem 3.1 does not work for this example. We know that a G-metric naturally 
induces a metric $d_{G}$ given by $d_{G}(x, y)=G(x, y, y)+G(x, x, y)$ [2], but inequality (3.1) does not reduce to any metric inequality with the metric $d_{G}$ due to the condition that either $u \neq s$ or $v \neq t$. Hence our theorems are more general, different from the classical results, and do not reduce to fixed point problems in the corresponding metric space $\left(X, d_{G}\right)$.

\section{Acknowledgment}

The authors have benefited from the reports of the anonymous referees and they are thankful for their valuable comments on the first draft of this paper which improved the presentation and readability.

\section{References}

[1] S. Banach, "Sur les opérations dans les ensembles abstraits et leur application aux équations intégrales," Fundamenta Mathematicae, vol. 3, pp. 133-181, 1922.

[2] Z. Mustafa and B. Sims, "A new approach to generalized metric spaces," Journal of Nonlinear and Convex Analysis, vol. 7, no. 2, pp. 289-297, 2006.

[3] Z. Mustafa, H. Obiedat, and F. Awawdeh, "Some fixed point theorem for mapping on complete Gmetric spaces," Fixed Point Theory and Applications, vol. 2008, Article ID 189870, 12 pages, 2008.

[4] Z. Mustafa and B. Sims, "Fixed point theorems for contractive mappings in complete G-metric spaces," Fixed Point Theory and Applications, vol. 2009, Article ID 917175, 10 pages, 2009.

[5] S. A. Mohiuddine and A. Alotaibi, "Some results on tripled fixed point for nonlinear contractions in partially ordered G-metric spaces," Fixed Point Theory and Applications, vol. 2012, Article ID 179, 2012.

[6] M. Abbas, A. R. Khan, and T. Nazir, "Coupled common fixed point results in two generalized metric spaces," Applied Mathematics and Computation, vol. 217, no. 13, pp. 6328-6336, 2011.

[7] M. Abbas, Y. J. Cho, and T. Nazir, "Common fixed points of ciric-type contractive mappings in two ordered generalized metric spaces," Fixed Point Theory and Applications, vol. 2012, article 139, 2012.

[8] M. Abbas, W. Sintunavarat, and P. Kumam, "Coupled fixed point of generalized contractive mappings on partially ordered G-metric spaces," Fixed Point Theory and Applications, vol. 2012, article 31, 2012.

[9] H. Aydi, B. Damjanović, B. Samet, and W. Shatanawi, "Coupled fixed point theorems for nonlinear contractions in partially ordered G-metric spaces," Mathematical and Computer Modelling, vol. 54, no. 9-10, pp. 2443-2450, 2011.

[10] B. S. Choudhury and P. Maity, "Coupled fixed point results in generalized metric spaces," Mathematical and Computer Modelling, vol. 54, no. 1-2, pp. 73-79, 2011.

[11] N. V. Luong and N. X. Thuan, "Coupled fixed point theorems in partially ordered G-metric spaces," Mathematical and Computer Modelling, vol. 55, no. 3-4, pp. 1601-1609, 2012.

[12] R. P. Agarwal, M. A. El-Gebeily, and D. O'Regan, "Generalized contractions in partially ordered metric spaces," Applicable Analysis, vol. 87, no. 1, pp. 109-116, 2008.

[13] I. Altun and A. Erduran, "Fixed point theorems for monotone mappings on partial metric spaces," Fixed Point Theory and Applications, vol. 2011, Article ID 508730, 10 pages, 2011.

[14] T. G. Bhaskar and V. Lakshmikantham, "Fixed point theorems in partially ordered metric spaces and applications," Nonlinear Analysis. Theory, Methods E Applications, vol. 65, no. 7, pp. 1379-1393, 2006.

[15] B. S. Choudhury and A. Kundu, "A coupled coincidence point result in partially ordered metric spaces for compatible mappings," Nonlinear Analysis. Theory, Methods \& Applications, vol. 73, no. 8, pp. 2524-2531, 2010.

[16] L. Ćirić, N. Cakic, M. Rajovic, and J. S. Ume, "Monotone generalized nonlinear contractions in partially ordered metric spaces," Fixed Point Theory and Applications, vol. 2009, Article ID 131294, 11 pages, 2008.

[17] V. Lakshmikantham and L. Cirić, "Coupled fixed point theorems for nonlinear contractions in partially ordered metric spaces," Nonlinear Analysis. Theory, Methods \& Applications, vol. 70, no. 12, pp. 4341-4349, 2009.

[18] H. K. Nashine and W. Shatanawi, "Coupled common fixed point theorems for a pair of commuting mappings in partially ordered complete metric spaces," Computers \& Mathematics with Applications, vol. 62, no. 4, pp. 1984-1993, 2011. 
[19] J. J. Nieto and R. Rodríguez-López, "Contractive mapping theorems in partially ordered sets and applications to ordinary differential equations," Order, vol. 22, no. 3, p. 223-239 (2006), 2005.

[20] J. J. Nieto and R. Rodríguez-López, "Existence and uniqueness of fixed point in partially ordered sets and applications to ordinary differential equations," Acta Mathematica Sinica, vol. 23, no. 12, pp. 2205-2212, 2007.

[21] A. C. M. Ran and M. C. B. Reurings, "A fixed point theorem in partially ordered sets and some applications to matrix equations," Proceedings of the American Mathematical Society, vol. 132, no. 5, pp. 1435-1443, 2004.

[22] B. Samet, "Coupled fixed point theorems for a generalized Meir-Keeler contraction in partially ordered metric spaces," Nonlinear Analysis. Theory, Methods \& Applications, vol. 72, no. 12, pp. 45084517, 2010.

[23] W. Sintunavarat and P. Kumam, "Weak condition for generalized multi-valued $(f, \alpha, \beta)$-weak contraction mappings," Applied Mathematics Letters, vol. 24, no. 4, pp. 460-465, 2011.

[24] W. Sintunavarat, Y. J. Cho, and P. Kumam, "Coupled fixed point theorems for weak contraction mappings under F-invariant set," Abstract and Applied Analysis, vol. 2012, Article ID 324874, 15 pages, 2012.

[25] N. V. Luong and N. X. Thuan, "Coupled fixed points in partially ordered metric spaces and application," Nonlinear Analysis. Theory, Methods \& Applications, vol. 74, no. 3, pp. 983-992, 2011. 


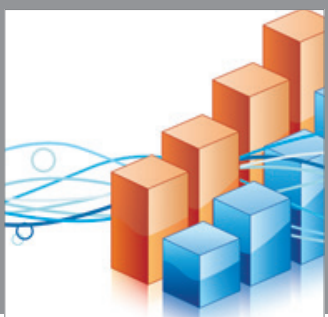

Advances in

Operations Research

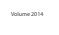

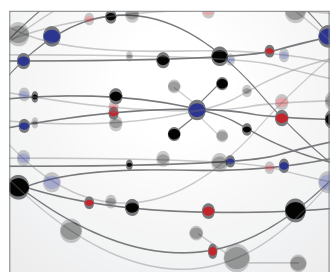

\section{The Scientific} World Journal
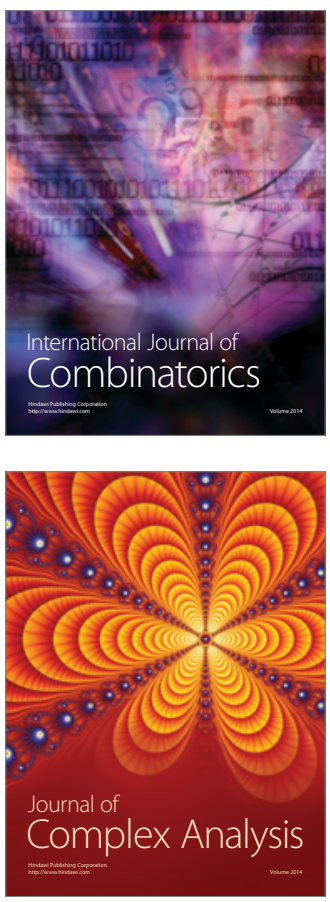

International Journal of

Mathematics and

Mathematical

Sciences
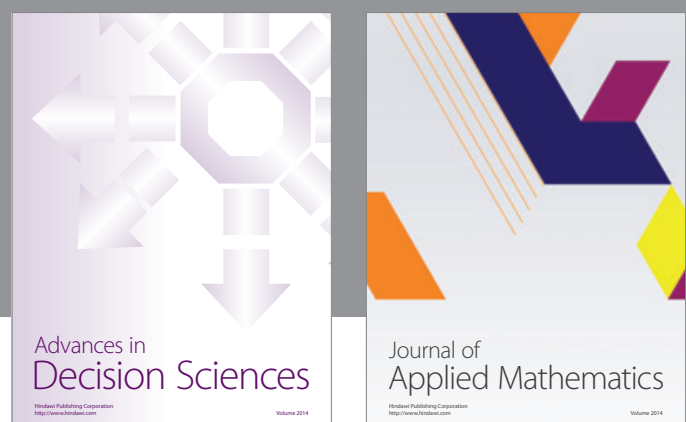

Journal of

Applied Mathematics
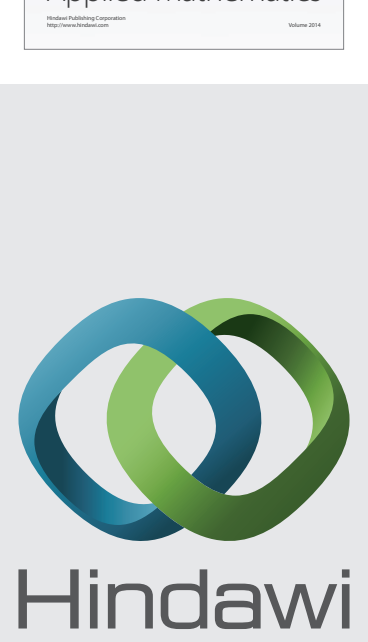

Submit your manuscripts at http://www.hindawi.com
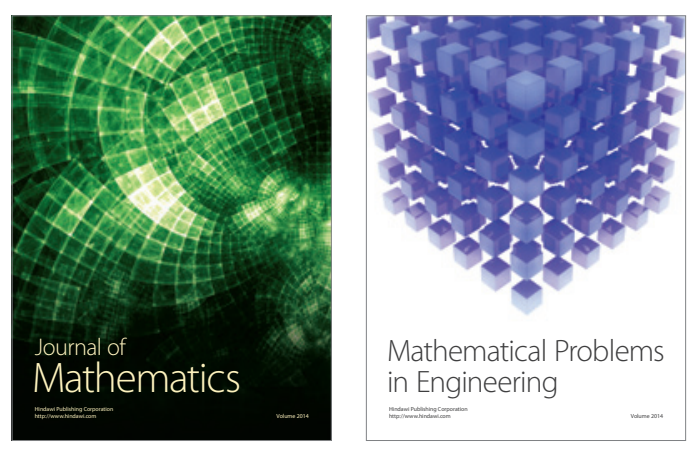

Mathematical Problems in Engineering
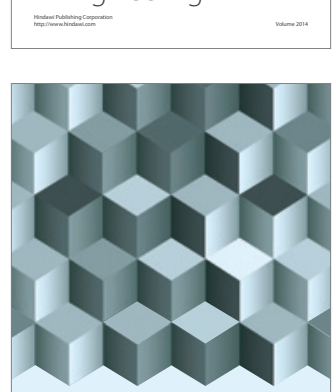

Journal of

Function Spaces
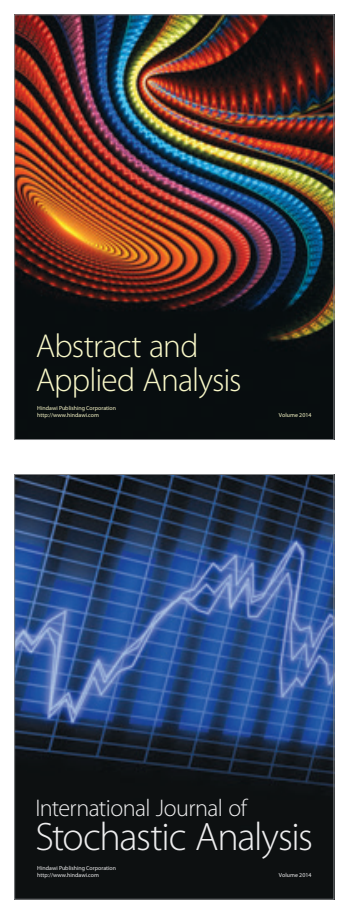

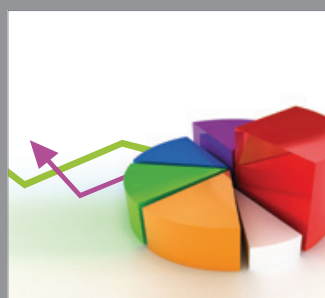

ournal of

Probability and Statistics

Promensencen
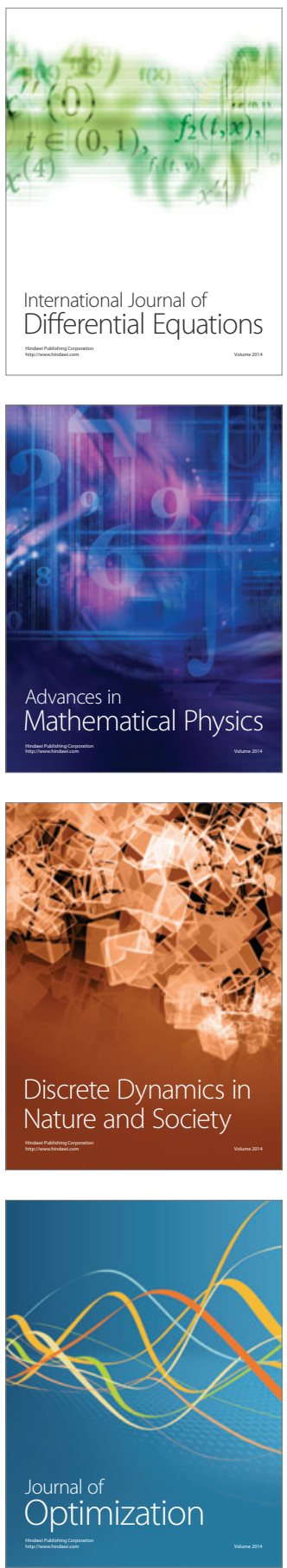